\title{
Penilaian Resiliensi Dimensi Sosial Berdasarkan Konsep Climate and Disaster Resilience Initiative (CDRI)
}

\author{
Mega Utami Ciptaningrum dan Adjie Pamungkas \\ Departemen Perencanaan Wilayah dan Kota, Fakultas Teknik Sipil dan Perencanaan, Institut \\ Teknologi Sepuluh Nopember (ITS) \\ e-mail: adjie@urplan.its.ac.id
}

\begin{abstract}
Abstrak-Banjir akibat meluapnya Kali Lamong selalu berdampak terhadap 2 wilayah perkotaan di Kabupaten Gresik, yaitu wilayah perkotaan Desa Cerme Kidul dan Desa Bulurejo. Banjir tahun 2014 hingga 2015, telah merendam sebanyak 30 rumah, 110 ha sawah dan 105 ha tambak di Desa Cerme Kidul. Sedangkan di Desa Bulurejo, banjir telah merendam 300 rumah dan 41 ha sawah, serta merendam pasar Benjeng dan beberapa fasilitas umum. Tren dalam menghadapi bencana saat ini lebih ditekankan pada upaya peningkatan resiliensi bencana karena lebih menghemat biaya. Untuk merumuskan arahan adaptasi peningkatan resiliensi sosial yang sesuai perlu dilakukannya penilaian terhadap level resiliensi eksisting terlebih dahulu. Konsep Climate and Disaster Resilience Initiative (CDRI) dipilih untuk menilai resiliensi dalam penelitian ini karena kesesuaiannya dengan kondisi wilayah penelitian. Dimensi sosial menjadi fokus utama dalam penelitian ini karena merupakan kunci utama peningkatan resiliensi masyarakat dalam menghadapi bencana. Artikel ini merupakan bagian dari penelitian mengenai penentuan arahan adaptasi peningkatan resiliensi dimensi sosial di wilayah perkotaan desa Bulurejo dan Desa Cerme Kidul terhadap banjir luapan Kali Lamong. Melalui analisis terhadap kuesioner menggunakan skala likert dan deskriptive kualitatif diperoleh nilai resiliensi kedua wilayah perkotaan tersebut. Hasil penelitian menunjukkan bahwa tingkat resiliensi kedua desa tersebut termasuk dalam level tinggi. Namun Desa Cerme Kidul lebih resilien jika dibandingkan dengan Desa Bulurejo.
\end{abstract}

Kata Kunci-Perkotaan, Resiliensi, Dimensi sosial, Climate and Disaster Resilience Initiative (CDRI).

\section{PENDAHULUAN}

$\mathrm{B}$ ANJIR adalah bencana alam yang sering terjadi di Indonesia dan menimbulkan kerusakan sebesar dua per tiga dari bencana alam yang pernah terjadi [1]. Selain itu, banjir juga mengganggu kelancaran aktivitas manusia, menimbulkan korban jiwa, kerugian materi serta efek psikologis (trauma) terhadap pihak yang terdampak [2].

Bencana banjir kerap terjadi di Kabupaten Gresik. salah satunya disebabkan karena luapan Kali Lamong. Wilayah perkotaan yang terdampak luapan Kali Lamong adalah Desa Bulurejo dan Desa Cerme Kidul. Kerugian akibat banjir tahun 2015 di Desa Bulurejo antara lain terendamnya 300 rumah, 900 warga terdampak, 41 ha sawah terendam, pasar dan kantor pemerintahan terendam dengan ketinggian air maksimum 65 $\mathrm{cm}$. Sedangkan di Desa Cerme Kidul berdampak pada 150 warga, 30 rumah, 110 ha sawah dan 105 ha tambak terendam dengan ketinggian maksimum $30 \mathrm{~cm}$ [3]

Pengurangan risiko bencana lebih ditekankan pada peningkatan resiliensi. Resiliensi adalah kemampuan sistem atau masyarakat yang terdampak bencana untuk memulihkan diri secara cepat dan efisien [4]. Penilaian resiliensi wilayah terhadap bencana penting dilakukan untuk mengetahui kondisi resilieni eksisting dan sebagai dasar dalam dalam merumuskan arahan adaptasi peningkatan resiliensi. Dari beberapa konsep yang ada, Climate and Disaster Resilience Initiative (CDRI) merupakan konsep yang paling sesuai untuk menilai resiliensi di wilayah penelitian. Hal ini dikarenakan fungsi spesifik konsep CDRI yang hanya digunakan untuk mengukur tingkat resiliensi di kota-kota Asia-Pasifik dan khusus untuk bencana hidrometeorologi [5]. Pengukuran resiliensi difokuskan hanya pada dimensi sosial, karena resiliensi terhadap bencana alam dapat diperoleh melalui keterkaitan atau koneksi antar manusia, bukan berasal dari infrastruktur fisik atau perlengkapan peralatan dalam menghadapi bencana [6].

\section{METODOLOGI PENELITIAN}

\section{A. Metode pengumpulan data}

Metode pengumpulan data yang digunakan dalam penelitian ini adalah metode survei primer dan survei sekunder. Survei primer dilakukan dengan pengisian kuesioner CDRI oleh stakeholder yang terpilih dari pihak internal di masing-masing desa. Kuesioner memuat 5 indikator yang masing-masing indikator memiliki 5 variabel. Sehingga terdapat 25 variabel untuk mengukur resiliensi sosial menurut konsep CDRI [5]. Stakeholder terpilih di Desa Bulurejo dari pihak pemerintah adalah dari kantor kecamatan (Ga1), kantor desa (Ga2), dan Badan Permusyawaratan Desa (Ga3). Dari pihak masyarakat adalah dari pengurus RW (Ca1) dan pengurus RT (Ca2). Sedangkan dari pihak swasta adalah Gabungan Kelompok Tani (Pa1). Begitu pula dengan Desa Cerme Kidul, stakeholder dari pihak pemerintah adalah dari kantor kecamatan (Gb1), kantor desa (Gab2), dan Badan Permusyawaratan Desa (Gb3). Dari pihak masyarakat adalah dari pengurus RW $(\mathrm{Cb} 1)$ dan pengurus RT $(\mathrm{Cb} 2)$. Sedangkan 
dari pihak swasta adalah Gabungan Kelompok Tani (Pb1). Sementara itu, survei sekunder dilakukan melalui survei instansional untuk mengetahui gambaran umum wilayah dan data kebencanaan di wilayah penelitian. Peta wilayah penelitian sebgaaimana ditunjukkan pada gambar berikut.

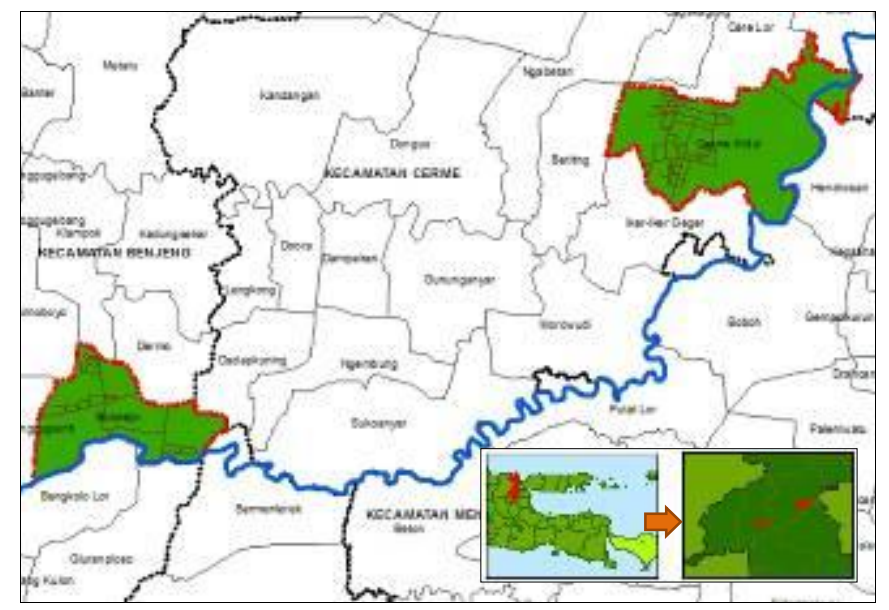

Gambar 1. Peta wilayah penelitian.

\section{B. Metode Analisis}

Metode analisis yang digunakan adalah skala Likert dengan nilai 1 (sangat rendah) hingga 5 (sangat rendah) dan penilaian terhadap bobot pengaruh variabel terhadap peningkatan resiliensi sosial. Skala Likert digunakan untuk mengukur sikap, pendapat dan persepsi seseorang atau sekelompok orang tentang fenomena sosial [8]. Berdasarkan penilaian responden akan diperoleh 2 macam karakter nilai, yaitu :

1. Nilai dari seluruh responden memiliki kemiripan atau hampir sama. Nilai ini berkisar antara sangat rendah (1) hingga sedang (3) atau sedang (3) hingga sangat tinggi (5).

2. Nilai dari responden memiliki perbedaan yang signifikan. Nilai ini ditunjukkan dengan adanya nilai yang berlawanan seperti terdapatnya nilai tinggi (4) dan rendah (2) atau nilai sangat tinggi (5) dan sangat rendah (1).

Karena adanya perbedaan tipe nilai yang akan diperoleh, maka akan terdapat pula perbedaan proses analisis yang dilakukan.

1. Nilai yang hampir sama langsung dilakukan interpretasi dengan merata-ratakan nilai mempertimbangkan bobot.

2. Nilai dengan perbedaan signifikan perlu dijustifikasi oleh peneliti berdasarkan nilai mayoritas dan beberapa alasan rasional beserta data pendukung lainnya. Setelah diperoleh nilai yang sesuai, dilakukan interpretasi dengan merataratakan nilai mempertimbangkan bobot.

Interpretasi nilai resiliensi masyarakat terhadap bencana banjir adalah sebagai berikut.

Nilai indeks :

$\frac{\sum_{i=1}^{n} w_{i} x_{i}}{\sum_{i=1}^{n} w_{i}}=\frac{\left(w_{1} \times x_{1}\right)+\left(w_{2} \times x_{2}\right)+\left(w_{a} \times x_{2}\right)+\left(w_{4} \times x_{4}\right)+\left(w_{5} \times x_{5}\right)}{w_{1}+w_{2}+w_{2}+w_{4}+w_{5}}$

Keterangan :

$\mathrm{w}_{1}=$ bobot 1

$\mathrm{W}_{2}=$ bobot 2

$\mathrm{W}_{3}=$ bobot 3

$\mathrm{x}_{1}=$ nilai 1

$\mathrm{w}_{4}=$ bobot 4

$\mathrm{x}_{2}=$ nilai 2

$\mathrm{W}_{5}=$ bobot 5

$\mathrm{x}_{3}=$ nilai 3

$\mathrm{x}_{4}=$ nilai 4

$\mathrm{x}_{5}=$ nilai 5
Nilai akhir yang telah diperoleh selanjutnya akan dibandingkan antara Desa Bulurejo dan Desa Cerme Kidul.

\section{HASIL DAN PEMBAHASAN}

\section{A. Analisis penilaian variabel}

Hasil pengisian kuesioner oleh responden dikategorikan menjadi 2 tipe, yaitu variabel yang dapat langsung dirataratakan dan variabel yang tidak bisa dirata-ratakan karena memiliki perbedaan nilai yang signifikan sehingga perlu dilakukan justifikasi. Hasil penilaian dari variabel yang dapat langsung dirata-ratakan di Desa Bulurejo ditampilkan pada tabel berikut.

Tabel 1.

Proses penilaian pada variabel yang dapat langsung dirata-ratakan di Desa Bulurejo

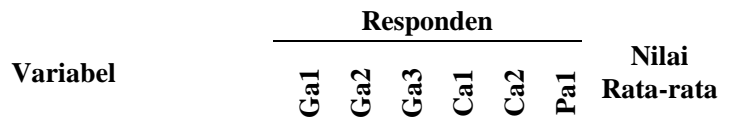

\section{a. Populasi}

Pertumbuhan penduduk

Populasi usia di bawah 14 tahun

$\begin{array}{llllllll}5 & 5 & 5 & 5 & 5 & 5 & 5\end{array}$

Populasi usia di atas 64 tahun

Populasi penduduk di

permukiman informal

Kepadatan penduduk

$\begin{array}{lllllll}3 & 3 & 3 & 3 & 3 & 3 & 3\end{array}$

$\begin{array}{llllllll}5 & 5 & 5 & 5 & 5 & 5 & 5\end{array}$

b. Kesehatan

Akses ke fasilitas kesehatan terdekat

Keberfungsian fasilitas kesehatan setelah terjadinya bencana

Kemampuan sistem layanan

kesehatan dalam persiapan

menghadapi banjir

c. Pendidikan dan kesadaran terhadap bencana

Angka melek huruf (AMH)

Jumlah populasi yang sadar

terhadap bencana

Keberfungsian sekolah setelah

terjadinya bencana

$\begin{array}{lllllll}3 & 3 & 5 & 3 & 5 & 3 & 4\end{array}$

$\begin{array}{lllllll}4 & 4 & 4 & 4 & 4 & 4 & \end{array}$

d. Modal sosial

Kemampuan komunikasi

penduduk untuk mencapai

konsensus

Kemampuan penduduk dalam proses pengambilan keputusan (level demokrasi)

Keberbauran antara satu

kelompok sosial dengan

kelompok sosial lainnya

e. Kebersatuan sosial dan kesiapsiagaan terhadap bencana

Kesiapan logistik, material, manajemen bencana

Jumlah populasi yang

berpartisipasi meringankan

$\begin{array}{llllll}4 & 5 & 4 & 5 & 5 & 4\end{array}$

4,57

$\begin{array}{llllll}5 & 5 & 3 & 5 & 5 & 5\end{array}$

4,58

kegiatan (relawan)

Dari 25 variabel yang ada, terdapat 16 variabel yang dapat langsung dirata-ratakan dengan mempertimbangkan bobot. Sedangkan 9 variabel lainnya memiliki perbedaan nilai yang signifikan sehingga perlu justifikasi dari peneliti berdasarkan data-data pendukung lainnya. Dengan pembulatan hingga 0 angka di belakang koma maka terdapat 1 variabel di kategori 
sedang, 11 variabel tinggi dan 4 variabel sangat tinggi dari 16 variabel yang dapat langsung dirata-ratakan.

\section{B. Analisis justifikasi penilaian}

Variabel yang tidak bisa langsung dirata-ratakan dilakukan justifikasi terhadap nilai yang paling banyak muncul yang didukung oleh data-data dan pernyataan dari responden.

Tabel 2.

Penilaian resiliensi sosial Desa Bulurejo pada variabel yang nilainya tidak bisa dirata-rata (memiliki perbedaan nilai yang signifikan) di Desa Bulurejo

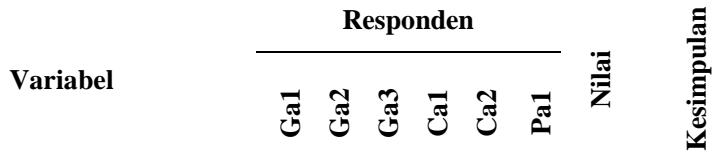

a. Populasi

b. Kesehatan

Populasi penduduk yang mengalami sakit akibat pencemaran air banjir (waterborne disease)

Mayoritas responden menilai 3. Bulan banjir biasa terjadi bulan Februari dan Maret. Sesuai data pasien rawat inap Puskesmas Benjeng, pada bulanbulan tersebut terdapat cukup banyak pasien rawat inap di Puskesmas Benjeng. Dalam satu tahun, sebanyak $21 \%$ pasien menjalani rawat inap pada bulan Februari hingga Maret di Puskesmas Benjeng [9]. Sehingga nilai 3 dianggap sesuai dengan kondisi eksisting.

Kapasitas tampung fasilitas

$\begin{array}{llllllllll}\text { kesehatan selama terjadinya } & 2 & 3 & 3 & 4 & 4 & 5 & 4 & \text { Tinggi }\end{array}$

bencana

Mayoritas responden menilai 4. Puskesmas Benjeng termasuk fasilitas kesehatan tingkat pertama tipe Puskesmas rawat inap yang melayani 15 desa. Puskesmas ini juga telah ditunjang dengan fasilitas dan tenaga medis yang mencukupi [9]. Rata-rata dalam satu bulan dapat menampung 35 pasien rawat inap dan dalam satu tahun dapat menampung hingga 415 pasien rawat inap [8]. Sehingga nilai 4 dianggap sesuai dengan kondisi eksisting.

c. Pendidikan dan kesadaran terhadap bencana

Tersedianya program atau

pelatihan kesadaran terhadap

$5 \quad 4 \quad 5$

bencana

Mayoritas responden masyarakat menilai 1 . Namun pihak pemerintah menilai 4 dan 5. Menurut asumsi peneliti yang juga diperkuat pernyataan beberapa responden $(\mathrm{Ga} 2, \mathrm{Ga} 3)$, program pelatihan telah berjalan namun informasi dan transfer ilmu yang diperoleh tidak sampai menjangkau ke masyarakat tingkat bawah terutama masyarakat yang terdampak banjir. Salah satu pernyataan responden adalah sebagai berikut :

Kalau program dari kabupaten mendatangkan perwakilan desa sudah ada ... Nah mungkin, hasil yang mereka peroleh dari tingkat kabupaten ini yang belum diberikan kepada masyarakat ... Itu bulan lalu sudah ada perwakilan desa untuk diundang di tingkat kabupaten ... Nah materinya ya pelatihan tentang bencana (Sekretaris BPD, 130217).

Sehingga nilai 1 dianggap sesuai dengan kondisi eksisting.

$\begin{array}{llllllllll}\text { Akses internet } & 2 & 3 & 3 & 5 & 2 & 4 & 3 & \text { Sedang }\end{array}$

Mayoritas responden menilai 3 dan 2. Menurut responden, akses internet mayoritas dimiliki penduduk usia sekolah, seperti pernyataan berikut :

Yang punya internet anak sekolahan itu rata-rata punya semua (Sekretaris Desa, 130217)

Penduduk usia sekolah antara 6 hingga 25 tahun sebanyak 1.228 jiwa atau setara dengan $29,9 \%$ [10]. Sehingga nilai 3 dianggap sesuai dengan kondisi eksisting.

d. Modal sosial

Jumlah penduduk yang tergabung dalam komunitas

$\begin{array}{llllllll}3 & 3 & 3 & 5 & 1 & 3 & 3 & \text { Sedang }\end{array}$

Mayoritas responden menilai 3. Responden (Ga3, Ca1) menilai komunitas

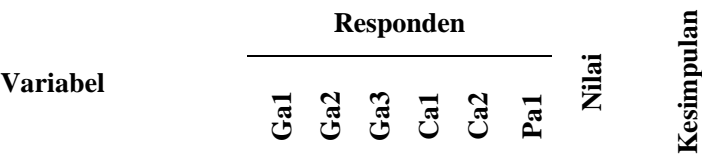

dan kegiatan yang ada hanya bersifat rutinitas untuk menyambut hari-hari tertentu saja. Tidak terlalu banyak kegiatan-kegiatan rutin harian. Selain itu keterlibatan masyarakat khususnya pemuda belum terlalu tinggi karena disibukkan dengan pekerjaan masing-masing. Hal ini disampaikan dalam pernyataan berikut :

Kalau PKK tingkat RT, RW itu kayaknya nggak jalan. Hanya ada tingkat desa, itupun kayaknya nggak seberapa jalan juga. .......... Karang Taruna ada, tapi kegiatannya nggak terlalu kelihatan, karena di sini kesempatan kerjanya tinggi, jadi anak mudanya sibuk nggak punya kesempatan. Cuma kegiatan rutin saja, misalnya PHBI (Peringatan Hari Besar Islam) atau PHBN (Peringatan Hari Besar Nasional). Agustusan itu baru muncul Karang Tarunanya, bisa guyub gitu, rame gitu, ada kegiatan lomba buat hiburan. Tapi kalau masamasa peringatan itu habis ya hilang lagi nggak ada kegiatan. Ya sempat ada kegiatan arisan atau apa, tapi nggak bisa lancar gitu. Upaya-upaya untuk lebih memajukan atau meningkatkan itu saya rasa nggak ada, ya kayak tradisi aja, rutinitas aja (Kepala dusun, 130217).

Sehingga nilai 3 dianggap sesuai dengan kondisi eksisting.

Jumlah penduduk yang

$\begin{array}{lllllllll}\text { berpartisipasi dalam kegiatan } & 3 & 3 & 3 & 1 & 1 & 5 & 3 & \text { Sedang }\end{array}$ sosial

Sama seperti poin variabel jumlah penduduk yang tergabung dalam komunitas.

e. Kebersatuan sosial dan kesiapsiagaan terhadap bencana

Ketersediaan tempat

berlindung (shelter) untuk

masyarakat terdampak

bencana

Mayoritas responden menilai 5. Responden (Ga2, Pa1, Ca2) menyatakan bahwa dalam kondisi banjir hanya sebagian kecil yang mengungsi. Untuk tempat mengungsi, masyarakat juga lebih memilih kepada saudara atau tetangga terdekat saja. Shelter cenderung tidak begitu dibutuhkan, seperti pernyataan salah satu responden berikut :

Banjirnya Benjeng itu sudah berabad-abad kok, sudah turun-temurun. Sudah tau, jadi yang rumah terendam ini ngungsi ke rumah saudara. Orang itu nggak mau suruh ngungsi, paling yang ini pindah ke rumah RT sebelahnya. Nggak mau suruh ngungsi, karena pagi banjir sore sudah reda... (Camat Benjeng, 160217).

Sehingga nilai 5 dianggap sesuai dengan kondisi eksisting.

$\begin{array}{lllllllll}\text { Dukungan dari NGOs/CBOs } & 4 & 4 & 2 & 4 & 5 & 4 & 4 & \text { Tinggi }\end{array}$

Mayoritas responden menilai 4. Bantuan dari pihak non-pemerintah telah cukup banyak diterima.

Bantuan dari swasta, yang banyak. Kemarin itu ada dari komunitas ibuibu, terus dari UNIPA itu tiga kali ke sini, pertama satu truk mie instan, beras dan macam-macam sembako. Kemudian dari bank juga ada ... (Camat Benjeng, 160217)

Sehingga nilai 4 dianggap sesuai dengan kondisi eksisting.

$\begin{array}{lllllllllll}\text { Populasi penduduk yang } & 5 & 5 & 2 & 4 & 2 & 4 & 5 & \text { Sangat }\end{array}$ terevakuasi secara sukarela $\begin{array}{llllllll}5 & 5 & 2 & 4 & 2 & 4 & 5 & \text { tinggi }\end{array}$

Mayoritas responden menilai 4 dan 5. Evakuasi masyarakat terdampak banjir hanya dilakukan ketika banjir besar terjadi saja. Banjir yang terjadi akhir-akhir ini tidak sampai membutuhkan upaya evakuasi. Masyarakat lebih memilih bertahan di rumah masing-masing karena dianggap tidak berbahaya. Hal ini mengindikasikan proses evakuasi jiwa tidak terlalu dibutuhkan, sebagaimana pernyataan salah satu responden berikut :

Saya rasa kok belum perlu ya. Wong masyarakat itu sudah bisa menyelamatkan diri sendiri kok. Biasanya ya nggak sampai ngungsi begitu (Sekretaris desa, 130217).

Sehingga nilai 5 dianggap sesuai dengan kondisi eksisting.

Nilai akhir yang diperoleh untuk masing-masing variabel sangat beragam. Berdasarkan hasil penyesuaian dengan data pendukung, diperoleh 1 variabel berada dalam kategori sangat 
rendah, 4 variabel sedang, 2 variabel tinggi dan 2 variabel sangat tinggi.

\section{Interpretasi nilai resiliensi}

Berdasarkan hasil analisis yang telah dilakukan, diperoleh nilai resiliensi sosial untuk setiap variabel dan indikator. Nilai tersebut seperti ditunjukkan pada gambar diagram berikut.

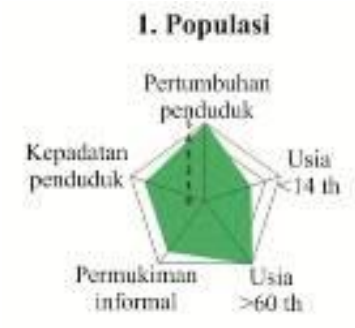

3. Pendidikan dan kesadaran

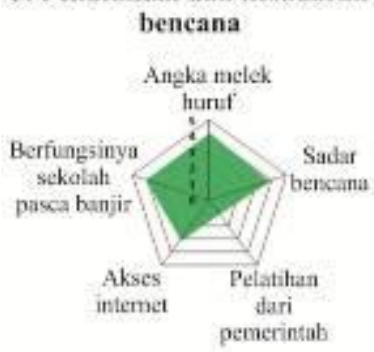

5. Kebersatuan sosial dan kesiapsiagaan

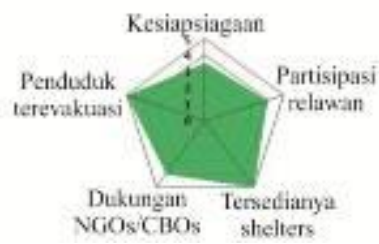

Gambar 3. Diagram nilai resiliensi variabel pada setiap indikator di Desa Bulurejo.

Jika dilihat dari hasil rata-rata keseluruhan variabel dalam tiap indikator, maka dapat diketahui bahwa nilai indikator resiliensi sosial di Desa Bulurejo sebagai berikut.

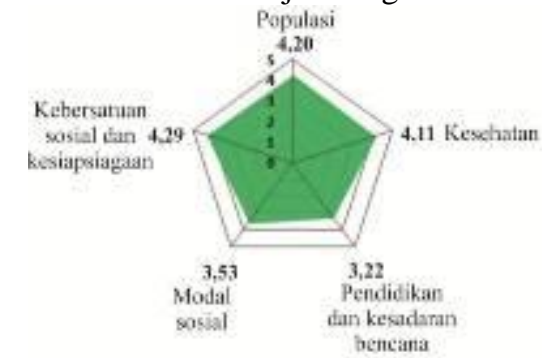

Gambar 4. Diagram nilai indikator resiliensi sosial Desa Bulurejo.

Rata-rata nilai pada lima indikator yang ada merupakan nilai akhir resiliensi sosial di Desa Bulurejo, yaitu 3,87 berada pada kategori tinggi. Karakter sosial masyarakat Desa Bulurejo antara lain masih perlu ditingkatkannya keanggotaan masyarakat pada komunitas dan partisipasi dalam kegiatan sosial. Selain itu dalam hal yang berkaitan dengan bencana perlunya upaya-upaya yang mendukung agar jumlah populasi yang sakit akibat tercemar air banjir berkurang. Perlunya penyebarluasan informasi dan pelatihan untuk menghadapi bencana kepada masyarakat hingga ke tingkat bawah serta peningkatan pemanfaatan teknologi informasi untuk mengurangi dampak bencana.

Cara yang sama diterapkan pula untuk menilai resiliensi sosial di Desa Cerme Kidul. Hasil nilai per variabel yang diperoleh adalah sebagai berikut.
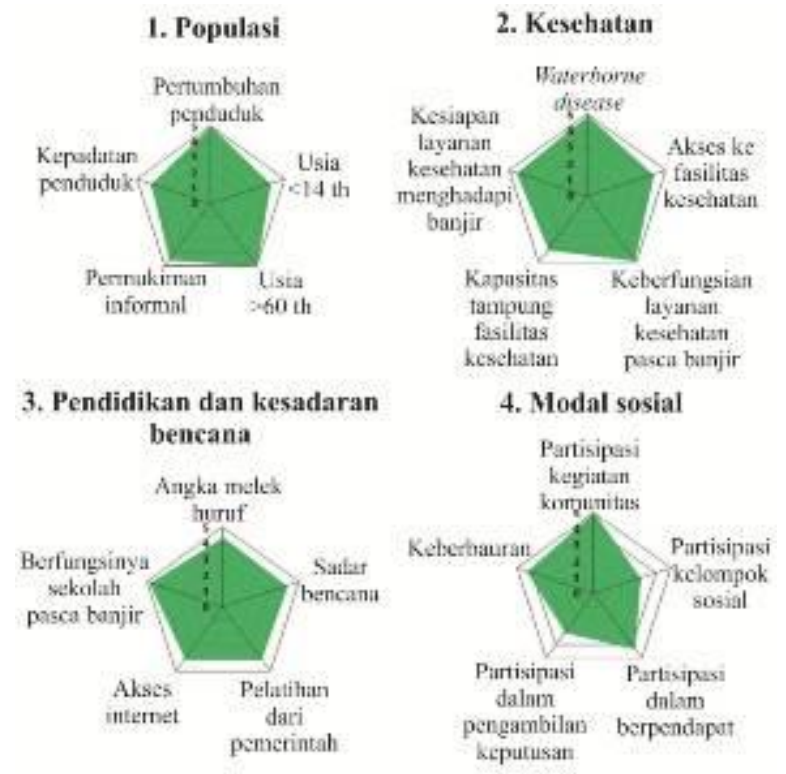

\section{Kebersatuan sosial dan kesiapsiagaan}

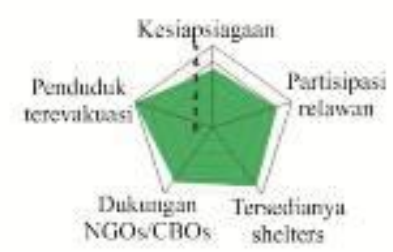

Gambar 5. Diagram nilai resiliensi variabel pada setiap indikator di Desa Cerme Kidul.

Jika dilihat dari hasil rata-rata keseluruhan variabel dalam tiap indikator, maka dapat diketahui bahwa nilai indikator resiliensi sosial di Desa Cerme Kidul sebagai berikut.

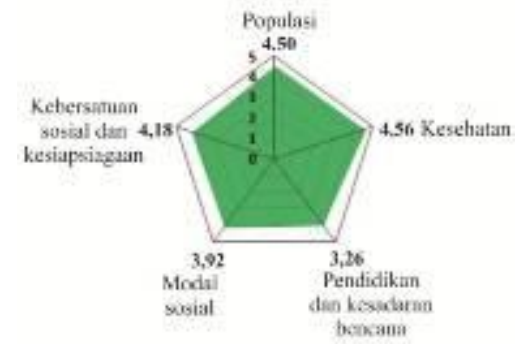

Gambar 6. Diagram nilai indikator resiliensi sosial Desa Cerme Kidul.

Rata-rata nilai pada lima indikator yang ada merupakan nilai akhir resiliensi sosial di Desa Cerme Kidul, yaitu 4,29 berada pada kategori tinggi. Karakter sosial masyarakat Desa Cerme Kidul antara lain meskipun masih cukup erat interaksi antar masyarakatnya namun partisipasi masyarakat dalam kegiatan sosial masih perlu ditingkatkan. Selain itu kemampuan dan 
keterlibatan penduduk dalam proses pengambilan keputusan (level demokrasi) juga masih perlu ditingkatkan. Akses informasi yang didukung oleh akses internet berada pada kategori tinggi, sehingga perlu dipertahankan dan dioptimalkan penggunaannya agar dapat mendukung upaya pengurangan dampak bencana banjir.

Berdasarkan hasil analisis penilaian resiliensi sosial dari kedua desa diketahui bahwa kedua desa merupakan wilayah perkotaan yang masih erat kegotong-royongan masyarakatnya. Hal ini diperkuat dengan masih cukup banyaknya interaksi dan kepedulian masyarakat terhadap tetangga dan lingkungan sekitarnya, terutama dalam kondisi banjir. Namun partisipasi masyarakat dalam kegiatan sosial masih perlu ditingkatkan. Hal ini salah satunya dipengaruhi oleh cukup tingginya kesempatan kerja masyarakatnya, sehingga kesempatan untuk terlibat dalam kegiatan sosial masih kurang.

\section{KESIMPULAN/RINGKASAN}

Berdasarkan hasil analisis dan pembahasan yang telah dilakukan pada penelitian ini, maka dapat disimpulkan bahwa:

1) Resiliensi sosial wilayah perkotaan Desa Bulurejo dan Desa Cerme Kidul terhadap banjir berada pada kategori tinggi.

2) Wilayah perkotaan Desa Cerme Kidul $(4,29)$ lebih resilien dibandingkan Desa Bulurejo $(3,87)$.

3) Indikator resiliensi sosial Desa Bulurejo dengan nilai tertinggi adalah indikator kebersatuan sosial dan kesiapsiagaan terhadap bencana $(4,29)$ dan indikator terendah adalah indikator pendidikan dan kesadaran terhadap bencana $(3,22)$.

4) Untuk meningkatkan resiliensi sosial di Desa Bulurejo dalam menghadapi bencana banjir perlu ditingkatkannya jumlah penduduk yang berpartisipasi dalam kegiatan sosial dan tergabung dalam komunitas, meningkatkan akses informasi, menyabarluaskan kemampuan kesadaran bencana dan mengupayakan pengurangan jumlah penduduk yang sakit karena tercemar air banjir.

5) Indikator resiliensi sosial Desa Cerme Kidul dengan nilai tertinggi adalah indikator kesehatan $(4,57)$ dan indikator terendah adalah indikator pendidikan dan kesadaran terhadap bencana $(3,26)$.

6) Untuk meningkatkan resiliensi sosial di Desa Cerme Kidul dalam menghadapi bencana banjir perlu ditingkatkannya partispasi masyarakat dalam kegiatan sosial serta meningkatkan kemampuan dan keterlibatan masyarakat dalam proses pengambilan keputusan.

\section{DAFTAR PUSTAKA}

[1] L. Indawati, "Analisis Tingkat Kerawanan Banjir dan Persepsi Masyarakat Terhadap Upaya Pengurangan Dampak Banjir di Kecamatan Baureno Kabupaten Bojonegoro," Universitas Sebelas Maret, 2015.

[2] et al Rakhman, A. A., Hestiningsih, D. D., Indriani, M., Sabrina, A., Kurniawati, A., B.S, Y. M., "Pemetaan Banjir Genangan di DAS Badegolan dengan Menggunakan Citra Landsat Multitemporal," Universitas Gadjah Mada, 2014.

[3] BPBD Kabupaten Gresik, Data kejadian banjir tahun 2014-2015. Gresik, 2015.

[4] UNISDR, "Resilience Terminology," UNISDR (Uniter Nations Office for Disaster Risk Reduction), 2017. [Online]. Available: http://www.unisdr.org/we/inform/terminology.

[5] S. A. S. R, Climate and Disaster Resilience in Cities. Bingley: Emerald Group Publishing Limited, 2011.

[6] D. P. Aldrich, "In Disaster Recovery, Social Networks Matter More Than Bottled Water and Batteries," 2017. [Online]. Available: www.citylab.com:

http://www.citylab.com/cityfixer/2017/02/recovering-fromdisasters-social-networks-matter-more-than-bottled-water-andbatteries/516726/. 